\title{
AC 2007-1349: ENGINEERING OUR FUTURE NEW JERSEY
}

\section{Liesl Hotaling, Stevens Institute of Technology}

Liesl Hotaling is Assistant Director of the Center for Innovation in Engineering and Science Education (CIESE), Stevens Institute of Technology. She received a B.S. in Marine Science from Fairleigh Dickinson University, a M.A.T. in Science Teaching from Monmouth University and a M.S. in Maritime Systems from Stevens.

\section{Beth McGrath, Stevens Institute of Technology}

Beth McGrath is Director of CIESE, where she manages program development and implementation and guides collaborations with K-12 schools and other educational partners. She is also leading the RIEE, Research \& Innovation in Engineering Education, initiative at Stevens, aimed at strengthening teaching and learning in undergraduate education at Stevens.

\section{Mercedes McKay, Stevens Institute of Technology}

Mercedes McKay is the Associate Director of the Center for Innovation in Engineering and Science Education (CIESE), Stevens Institute of Technology. She earned a B.S. in Mechanical Engineering from Carnegie-Mellon University and a graduate certificate in Technology Applications in Science Education from Stevens Institute of Technology.

\section{Carol Shields, Stevens Institute of Technology}

Carol Shields is responsible for teacher training and developing Internet-based curriculum materials for the elementary level. Ms. Shields taught for 26 years in the Bridgewater-Raritan School District. She has also worked in the school programs department at Liberty Science Center and as a marine life instructor for the National Audubon Society.

\section{Susan Lowes, Columbia University}

Dr. Susan Lowes, Institute for Learning Technologies, Teachers College, Columbia University, will conduct formative and summative evaluations over the three years. ILT has conducted evaluations of projects that develop, test, and implement new pedagogical approaches in the university, K-12, and community and after school environments, including those funded by NSF, the U.S. Dept. of Education, and others.

\section{Christine Cunningham, Museum of Science, Boston}

Christine M. Cunningham is the Vice President of Research at the Museum of Science, Boston. She has been developing science and engineering curriculum, designing and offering teacher professional development programs, and conducting research and assessment related to the learning and teaching of science and engineering for over 15 years. Christine is particularly interested in making science and engineering more accessible to marginalized populations. Christine received a joint Bachelors and Masters degree in Biology from Yale University and a Ph.D. in Science Education from Cornell University.

\section{Cathy Lachapelle, Museum of Science, Boston}

Dr. Cathy Lachapelle currently leads the assessment efforts for the EiE curriculum, designing assessment instruments, pilot and field testing them, and conducting research on how children use the EiE materials. She has worked on a number of research and evaluation projects related to K-16 engineering education. Cathy received her S.B. in cognitive science from MIT, and her Ph.D. in Psychological Studies in Education from Stanford University. 
Research Associate of the National Center for Technological Literacy (NCTL), Museum of Science, Boston.

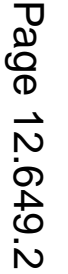




\title{
Engineering Our Future New Jersey
}

\begin{abstract}
Engineering Our Future New Jersey (EOFNJ) is a collaborative effort between Stevens Institute of Technology, the New Jersey Department of Education, the Museum of Science (MoS), Boston's National Center for Technological Literacy (NCTL), and other partners to bring exemplary technology and engineering curricula to mainstream New Jersey K-12 education. The goal of the Engineering Our Future New Jersey initiative is to ensure that all K-12 students in New Jersey experience engineering curricula with a focus on innovation, as a required component of their elementary, middle, and high school education within the next five years. In doing so, we aim to strengthen existing educational policy in New Jersey to articulate engineering competencies both in the language of the standards and the required assessments.
\end{abstract}

EOFNJ is transitioning from the pilot phase into a state-wide implementation phase. This paper provides an overview of the EOFNJ initiative, describes current activities, offers preliminary evaluation results and describes the exemplary curricula being promoted.

\subsection{Introduction}

Engineering Our Future New Jersey (EOFNJ) is an initiative of Stevens Institute of Technology's Center for Innovation in Engineering and Science Education (CIESE) to promote grade-appropriate engineering and technology education in elementary, middle, and high schools throughout New Jersey. With initial support from the State of New Jersey, CIESE launched an accelerated schedule to complete a pilot/demonstration phase, involving 35 teachers from 32 geographically, academically, and socio-economically diverse schools throughout New Jersey in 2005-06. With additional support from Verizon Communications and the National Science Foundation, CIESE is currently implementing Phase 2, the statewide scale-up phase, in which CIESE and its partners will provide professional development to 2,000 K-12 teachers throughout New Jersey in the next three years.

In collaboration with curriculum partners such as the Museum of Science, Boston's National Center for Technological Literacy and the Society of Automotive Engineers, Stevens is providing teacher professional development, technical assistance, and in-class support to participating schools. Other partners, including the New Jersey Department of Education, the New Jersey Principals and Supervisors Association, and other institutions of higher education, are also engaged in this outreach effort.

This paper describes the goals, strategies, and specific activities that the Center for Innovation in Engineering and Science Education (CIESE) at Stevens, together with partners, have developed and implemented in the context of the EOFNJ effort for elementary, middle, and high school teachers and students, and other educational stakeholders. 


\subsection{Pilot Phase}

The 2005-06 Pilot/Demonstration Phase of EOFNJ was conducted to 1) assess student identification and understanding of examples of engineering, 2) assess the underlying science and mathematics concepts of specified engineering curricula, 3) understand implementation challenges faced by teachers when integrating engineering modules into the classroom.

To prepare for the pilot study, CIESE staff first conducted a curriculum review to select gradeappropriate curricula which aligned with the science curriculum taught during the pilot implementation period (January-June 2006). Once a curriculum was identified, CIESE staff worked with the curriculum developers to condense or adapt materials to fit within a four-week implementation period and identify all of the pertinent NJ Core Curriculum Content Standards addressed by each of the selected curricula. Concurrently, external evaluators were contracted to design the evaluation model and instruments for each curriculum. After all pieces were in place, CIESE staff provided professional development workshops to the participating teachers.

The professional development workshops, conducted on December 1 and 2, 2005, were designed to accommodate teachers from each grade span, 13 elementary, 12 middle school, and 10 high school. The participants were gathered in a large group setting and given details about the EOFNJ program. Then participants broke into small work groups according to grade; elementary, middle and high school. In the small groups, participants learned about the curricula identified for use in the pilot. Teachers were led through the materials and given time to implement the project activities in a supported learning environment. Teachers received all the necessary materials to implement the curriculum in their classrooms.

The 35 teachers selected for the pilot study were expected to complete the following tasks:

- Attend a two-day teacher workshop.

- Deliver (teach) the selected modules as presented during the December workshops to students during the implementation window of January through June 2006, to allow for flexibility with individualized teaching plans.

- Receive CIESE staff into classrooms to support and observe implementation.

- Administer pre-tests and post-tests to students.

- Participate in a focus group about the effectiveness of the modules.

- Complete surveys regarding the implementation of the materials.

Upon completion of all the tasks outlined above, participating teachers received a $\$ 300.00$ stipend for their efforts.

\subsection{Elementary-Level Activities - Engineering is Elementary (EiE)}

The elementary curriculum selected for the pilot study was the Engineering is Elementary (EiE) series, developed by the Museum of Science, Boston's (MoS), National Center for Technological Literacy (NCTL). Each EiE module contains lessons that integrate an elementary school science topic with a specific field of engineering and feature hands-on activities that engage students in the engineering design process. Two modules were selected for the pilot program: 
(1) Water, Water, Everywhere (Environmental Engineering)

This module addresses the increasingly important issue of water quality through lessons that teach students about water contamination and the ways that people ensure the quality of their drinking water. Students plan, construct, test, and improve their own water filters.

(2) Catching the Wind (Mechanical Engineering)

This module guides students to learn about wind and the ways engineers design machines to capture wind energy. Students explore different materials and shapes conducive to catching the wind. For the design activity, students create their own windmills that can lift a small weight.

\subsection{Elementary School Pilot Study Results}

The EiE modules were used in thirteen New Jersey schools to assess the impact of gradeappropriate engineering curricula for elementary students. Evaluation of student learning resulting from use of the EiE modules was conducted by the MoS in the context of a national research effort to assess the impact of the EiE modules on student learning. The evaluation involved administering five pre-post assessments to gauge student understanding of the core science concepts and examples of engineering.

(1) Students significantly improved their ability to identify examples of technology and engineering. On the more difficult items to classify, students improved (between 11\% and 50\%) in their ability to correctly identify human-made items as examples of technology on the postassessment.

Students were given a series of questions, each of which presented a scenario where children were designing something, and asked which step of the engineering design process those children were engaged in or would proceed to next. On all questions, students were significantly more likely to choose the correct answers on the post-assessment than on the pre-assessment.

(2) Students significantly improved their ability to answer questions about water filters, filter materials and the science involved with the water filter module. Students were asked eight questions about water filters and water filter materials and six science content questions.

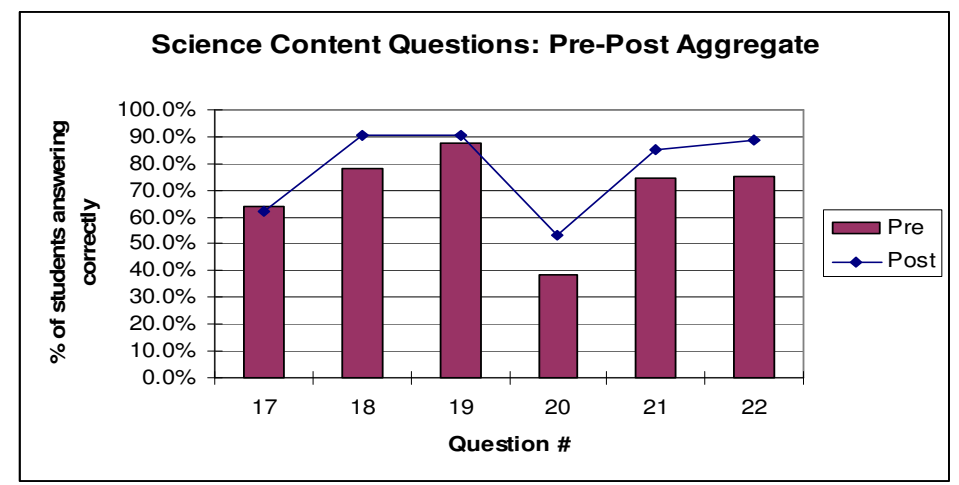

Table 1: Science Content Questions Students showed significant improvement on all but two of these questions. Of the two questions on which students did not improve, one appears to have been too easy for students, and the other was poorly worded and was revised for future assessments.

(3) Students improved their ability to answer questions about windmills and blade materials. Students performed consistently better on post-assessments than on pre-assessments but not all changes pre- to post- were significant. 
CIESE staff collected the reflections and observations of the teacher participants using informal surveys and classroom visits. A summary of teacher comments indicate:

- Teachers discovered that engineering concepts can be introduced at an early grade level.

- Teachers reported that students developed a better understanding of what engineers do.

- Teachers found the EiE lessons furthered objectives for science in the classroom and reinforced concepts already taught in class.

- Student understanding of science concepts improved as a result of interaction with the EiE materials.

- Teachers plan to integrate the EiE lessons into their existing science curriculum.

- Both teachers and students felt comfortable using the engineering design process.

- Students learned that there are different ways to solve problems.

- Students were active learners and motivation was positively affected; they were engaged and excited.

\subsection{Future Engineering is Elementary Implementation}

In Phase 2, the Statewide Scale-Up Phase, CIESE is developing partnerships with school districts, other institutions of higher education, and other STEM professional development providers to offer professional development for EiE modules in various locations around New Jersey to adequately prepare teachers to implement selected pre-engineering curricula in their respective classrooms. Currently, nine EiE modules have been published. There are eleven more in various stages of development. As future modules are released, CIESE and MoS staff will work together to bring the new modules to New Jersey classrooms.

\subsection{Middle School Level Activities - A World in Motion (AWIM)}

The Society of Automotive Engineer's A World in Motion - Challenge 2 curriculum was selected for use with middle school classrooms. The AWIM curriculum is designed around current national learning standards and offers highly interactive learning experiences. In Challenge 2, students receive a "Request for Proposals" from a company named "Mobility Toys, Inc." inviting design teams to design simple, mechanically propelled toys that appeal to children between the ages of 6-10. Activities weave together science, mathematics, technology, teamwork and communication skills, reinforcing key concepts such as force, motion, gears and gear trains, ratio, and others. Student design teams pool their talents to create a successful prototype and make a final presentation of their design rationale.

All participating pilot teachers received enough AWIM Student Kits and support materials to implement the curriculum. The kits were provided by the Society of Automotive Engineers Foundation. The AWIM Student Kits include the necessary parts (vehicle frame, motor, gears, axles, bushings, spacers and drive collars) for students to design and construct a chassis for their motorized toy. The teachers also received AWIM Teacher Kits (spring scales, AC adapter), a complete AWIM Challenge 2 curriculum binder, videos and posters as classroom support materials. In order to make the curriculum useful to a wide range of teachers, the existing eight week AWIM curriculum was condensed by CIESE and AWIM staff into a four week module. 


\subsection{Middle School Pilot Study Results}

The evaluation component of the AWIM Challenge 2 project was conducted by the Institute for Learning Technologies at Teachers College, Columbia University, and had several components designed to elicit problems as well as successes with AWIM Challenge 2. Eleven middle schools throughout New Jersey implemented the four-week module.

The pilot study teachers were asked to complete a short survey at the end of each of the five modules and another survey after the curriculum had been completed. In addition, although Challenge 2 contains a number of embedded assessments, it does not have pre- or post-tests. Therefore one pre-assessment on gears (adapted from a much more complex study by Dan Schwartz and John Black on mental models of physical systems) ${ }^{1}$ and two pre-post assessments on engineering and technology were added. Results are listed below in Table 2: Percent Correct.

\begin{tabular}{|c|c|c|c|}
\hline \multirow{2}{*}{ Grade } & \multicolumn{3}{|c|}{ Table 2: Percent correct } \\
\cline { 2 - 4 } & $\begin{array}{c}\text { Open Chain } \\
(\mathbf{O}-\mathbf{C})\end{array}$ & $\begin{array}{c}\text { Closed Chain } \\
(\mathbf{C}-\mathbf{C})\end{array}$ & $\begin{array}{c}\text { Long Chain } \\
(\mathbf{L}-\mathbf{C})\end{array}$ \\
\hline $\mathbf{6}^{\text {th }}(\mathbf{n = 4 4})$ & $59 \%$ & $36 \%$ & $43 \%$ \\
\hline $\mathbf{7}^{\text {th }}(\mathbf{n}=\mathbf{2 5})$ & $84 \%$ & $68 \%$ & $56 \%$ \\
\hline $\mathbf{8}^{\text {th }}(\mathbf{n = 1 3 6})$ & $71 \%$ & $61 \%$ & $45 \%$ \\
\hline Total & $69 \%$ & $56 \%$ & $45 \%$ \\
\hline
\end{tabular}

The pre-test of understanding of gears showed that few of the students in grades 6,7 and 8 understood open-chain $(\mathrm{O}-$ C) and long-chain (L-C) gear configurations. There was a significant difference between grades on the $\mathrm{O}-\mathrm{C}$ question ( $\mathrm{p}=.032$, which is less than .05) and $\mathrm{C}-\mathrm{C}(\mathrm{p}=.003$, which is less than .05) question, but not on the $\mathrm{L}-\mathrm{C}$ question. The 8th-grade students were anomalous in having trouble with the L-C problem.

The two pre-post assessments on engineering and technology were adapted from the Museum of Science, Boston's Engineering is Elementary curriculum. Table 3: What is technology and engineering? contains the percent correct on pre-test and post-test for all three grade levels.

\begin{tabular}{|c|l|r|r|r|r|}
\hline \multicolumn{2}{|c|}{ Table 3: } & \multicolumn{2}{c|}{$\begin{array}{c}\text { What is } \\
\text { technology? }\end{array}$} & \multicolumn{2}{c|}{$\begin{array}{c}\text { What is } \\
\text { engineering? }\end{array}$} \\
\hline Grade & & \multicolumn{1}{c|}{ Pre } & \multicolumn{1}{c|}{ Post } & \multicolumn{1}{c|}{ Pre } & \multicolumn{1}{c|}{ Post } \\
\hline \multirow{4}{*}{6} & Mean & .6497 & .6538 & .3910 & .4863 \\
\cline { 2 - 6 } & N & 42 & 39 & 43 & 41 \\
\cline { 2 - 6 } & Std. Dev. & .17313 & .18576 & .12507 & .18777 \\
\hline \multirow{4}{*}{7} & Mean & .7075 & .7675 & .5075 & .5525 \\
\cline { 2 - 6 } & N & 25 & 25 & 25 & 25 \\
\cline { 2 - 6 } & Std. Dev. & .21019 & .20214 & .15022 & .15168 \\
\hline \multirow{4}{*}{$\mathbf{8}$} & Mean & .7538 & .8595 & .4820 & .6619 \\
\cline { 2 - 6 } & N & 132 & 117 & 132 & 117 \\
\cline { 2 - 6 } & Std. Dev. & .21075 & .17580 & .19817 & .19423 \\
\hline \multirow{3}{*}{ Total } & Mean & .7256 & .8025 &. $\mathbf{4 6 5 6}$ & $\mathbf{. 6 0 7 6}$ \\
\cline { 2 - 6 } & N & 200 & 181 & 200 & 183 \\
\cline { 2 - 6 } & St. Dev. & .20665 & .19930 & .18297 & .20113 \\
\hline
\end{tabular}

All students had more difficulty with the engineering test than the technology test. At all grade levels and on both tests, the standard deviations were high, indicating a wide range of student responses. Despite these differences, the preand post-test results on both tests were highly correlated $(\mathrm{p}<.001)$. In other words, at the student level, a student who did well on one did well on all the others, and viceversa. The difference between grades was statistically significant; students in the higher grades did better than students in the lower grades, indicating that the tests do distinguish between grade levels. 
The results showed that student conceptions expanded between pre- and post-tests. In post-test results, student conceptions of engineering encompassed a broader range of activities than pretest. They were more likely to associate engineering with working in teams and invention.

Participant teacher comments were collected through survey responses and focus group sessions. A summary of the comments reveals that:

- All teachers reported either taking more than the allotted time or cutting some items in order to make the curriculum fit a four week period.

- Teachers made very few changes and there was no particular pattern to the changes they did make. However, many teachers came up with innovative ideas and additional material, including worksheets and templates.

- None of the pilot teachers reported that they already teach all the concepts covered in the curriculum. For some, the curriculum was a different way to cover existing material. For others, it was a useful follow-up to the more basic material they already teach.

- Although the evaluation did not address long-term student interest in physical science /engineering, all teachers reported that the students were enthusiastic about their projects.

The first major finding of the evaluation was that the Challenge 2 curriculum is extremely flexible. It was used in high-achieving classrooms, lower achieving classrooms, with special education students, and with ESL student; it was used primarily as a whole-class curriculum but also as a pull-out enrichment experience. Teachers were able to-and did-adapt it to the needs of their subject areas, curriculum content, and student learning levels. The project activities allowed students to contribute in different ways, from design (of the "company" logos) to keeping design logs, to building and testing equipment.

The second major finding was that the teachers uniformly reported that their students enjoyed the activities, and that this was equally true of boys and girls. Several teachers reported that some of the girls were reluctant at first but in the end, were just as competitive as the boys.

\subsection{Future AWIM Challenge 2 Implementation}

Implementation of the AWIM - Challenge 2 curriculum was so successful that three pilot schools have lobbied to adopt the curriculum district-wide. CIESE is currently supporting the school districts' adoption of the materials by offering free professional development to district teachers and facilitating procurement of equipment.

The New Jersey AWIM Challenge 2 will be supported by CIESE and the SAE Foundation for at least the next two school years. CIESE will continue to partner with school districts and offer professional development sessions in various locations throughout New Jersey to adequately prepare teachers to implement the curriculum in their respective classrooms. The SAE Foundation has committed to continue underwriting the costs for the AWIM Student and Teacher Kits and supporting materials in exchange for supplying evaluation data. 


\subsection{High School Activities - Engineering the Future Curriculum}

In the high school pilot, the Engineering the Future: Designing the World of the $21^{\text {st }}$ Century (EtF) curriculum produced by the Museum of Science, Boston (MoS), was implemented in 10 New Jersey high schools. Engineering the Future is a full-year introductory engineering course designed to provide a firm foundation in physics while increasing the technological literacy of all students. A central goal of the course is to develop students' practical understanding of how we are all influenced by technology and how we all influence future technological development by the choices we make as workers, consumers, and citizens.

Two modules were selected and adapted for implementation from the full-year EtF curriculum:

(1) Project 3: Fluid and Thermal Systems-Students investigate the topics of thermodynamics, energy transfer, fluid mechanics, work and motion as they construct a puttputt boat that runs using a fluid/thermal engine. Their challenge is to first understand how the engine works and then to re-design one aspect of the boat in order to improve its design. Students demonstrate learning by preparing patent applications to protect their creative ideas.

(2) Project 4: Electrical and Communication Systems-Students work with Snap Circuits, an electrical circuit kit in which components can be quickly and easily snapped together. Using switches, motors, speakers, resistors, light bulbs, and LEDs, students explore how electricity flows through different circuit arrangements and apply their understanding to a series of small design projects, including a rodent alarm and a multi-speed fan. Project 4 concludes with an exploration of electronic circuits useful for communication.

\subsection{High School Pilot Study Results}

Eleven teachers from ten high schools were selected for the pilot study. Physics, physical science, conceptual physics, honors physics, AP physics, technology, and pre-engineering teachers were all represented in the study and covered grades 9 through 12. Overall, 498 students from 17 classrooms (average class size of 29 students) participated in the EtF pilot study. One of the goals of the high school pilot was to see if the EtF curriculum could be successfully implemented in a variety of courses and over a shorter time frame than the full year course. This study was designed to evaluate the effectiveness of the program in improving the students' abilities to understand and apply the key concepts presented in the curriculum.

A comparison of pre-tests and post-tests indicated that the Engineering the Future curriculum effectively increased students' understanding of fluid/thermal and electrical systems. A majority of students demonstrated that they could make more accurate predictions, provide better explanations, and have more confidence after taking Module 3 on Fluid and Thermal Systems and Module 4 on Electrical Systems, than they could before the course.

The data analysis was based on the total number of students for whom we have the results of both pre- and post-tests. For Project 3 this number was 278 students. For Project 4 the number of students varied from 124 to 246. The results show that the Engineering the Future curriculum significantly improved students' ability to apply concepts of fluid/thermal systems and electricity to engineering projects. The determination of significance for all of the analyses was based on 
Pearson's chi-square tests. If $\mathrm{p}<.05$ we can be confident that the observed difference was not due to chance. Specific findings and supporting evidence are summarized below.

(1) Students significantly improved their ability to answer questions about fluid/thermal systems. For Project 3, there were seven questions included in both pre and post tests that were designed to assess students' understanding of fluid and thermal systems. The average percentage of correct answers to questions about fluid and thermal systems increased significantly from the pre-test $42.52 \%$ to the post-test $60.47 \%(\mathrm{p}<.000)$.

(2) Students significantly improved their ability to answer questions about electric circuits. For Project 4, there were 16 questions concerning simple circuits, series and parallel circuits, electric power and energy. The average percentage of correct answers to questions about electric circuits increased significantly from $52.65 \%$ to $65.7 \%$ from pre to post test $(\mathrm{p}<.000)$.

(3) Students significantly improved their ability to explain phenomena in electric circuits. For most of the questions in Project 4, students were also asked to explain their answers. These explanations were scored separately to determine if students were applying the correct model of electricity, not simply giving the right answer by chance. The average percentage of students who correctly explained different phenomena in various types of electric circuits increased significantly from $11.99 \%$ to $32.91 \%$ from the pre-test to the post-test $(\mathrm{p}<.000)$ indicates that students not only make improvement in understanding how circuits function, but also in their mental models of electrical phenomena.

(4) Students significantly improved their level of confidence in understanding electric circuits. Many of the questions in Project 4 also asked students about their confidence level when confronted with questions about electric circuits. The percentage of students who reported a high confidence level significantly increased from $34.25 \%$ to $53.85 \%$ from the pre-test to the post-test $(\mathrm{p}<.000)$. This finding suggests that the Engineering the Future curriculum successfully enhances students' confidence in understanding electric circuits.

\subsection{Insights and Recommendations}

The pre-test findings revealed that many students already possess some understanding of the content before instruction, which may result from life experience and/or prior instruction. However, many students also begin the course with fundamental misconceptions that may prevent them from correctly predicting what will occur in a specific situation, or more often, explaining how or why a phenomenon occurs. Since these misconceptions tend to be deep-seated mental models about the physical world, the challenge for the teacher is not simply to introduce new material, but to help their students replace their misconceptions with a more productive understanding of the phenomena.

The item analysis supports the findings of previous studies that many students have misconceptions about electricity, and that most of these erroneous ideas can be classified as one of a small number of common misconceptions, or incorrect mental models about electricity ${ }^{2,3,4}$. This finding can be very helpful to teachers since they will be able to anticipate the pitfalls that their students may encounter and devise different strategies for different misconceptions. They have also been taken into account in the next iteration of the EtF curriculum. 
These findings also suggest a general teaching strategy: to begin each new topic by encouraging students to discuss their initial thoughts about what would happen in a particular case and why. For example, before studying simple circuits, a class of students might be shown an electrical circuit and asked to explain whether a bulb will light or not. As suggested by previous investigators ${ }^{3,5}$, such discussions can be helpful for teachers by identifying any misconceptions that need to be replaced, and can help students become consciously aware of their current thinking, which is an important first step in the learning process. Subsequent instruction can then help students test their initial models in situations where they can gradually replace any misconceptions with a more productive scientific understanding.

\subsection{Future EtF Implementation}

The EtF full-year curriculum is currently in its final phase of pilot testing and the first version of the curriculum is scheduled for release in September 2007. In focus group discussions with the EOFNJ pilot teachers, most indicated that the EtF projects were very worthwhile and that their students were very engaged in the design efforts. Although all of the teachers were able to effectively integrate the modules into their courses, most felt they did not have enough time to devote to the projects given their course requirements. One teacher needed to augment the EtF curriculum with higher level math applications for his honors physics classes, recognizing that the EtF curriculum was not designed for that level. Two schools that participated in the EOFNJ pilot study have continued to use the curriculum. Other schools have indicated that they would be interested in implementing the full-year curriculum when available. CIESE will continue to recruit teachers to implement the original full-year version of the EtF curriculum and to partner with school districts and other universities to offer professional development sessions in various locations around New Jersey to adequately prepare teachers to implement the curriculum in their respective classrooms.

\subsection{Conclusion}

The goals of the Pilot/Demonstration phase of the Engineering Our Future New Jersey initiative were accomplished:

- Positive impact on student learning at all three levels

Results from pre-post assessments demonstrate positive student learning outcomes for identification of examples of engineering and the science, engineering and technology education skills included in the curricula. In addition, anecdotal comments gathered in classroom observations elicit student enthusiasm for the curricula used in the pilot.

- Correlation of engineering curricula with the NJ Core Curriculum Content Standards The science and mathematics concepts contained within the piloted curricula fit very well with NJ Core Curriculum. However, the current standards include only two technology standards, one of which marginally includes engineering. Based on the results of the pilot study and support from the New Jersey Department of Education, CIESE is advocating for increased and more clearly defined technology standards, and potentially new engineering standards in pending revisions of the NJ Core Curriculum Content Standards.

- Issues related to integration of engineering curricula into existing courses Participants faced minor implementation issues. For some participants, using the new curricula offered different ways to cover existing material. For other participants, the new curricula offered a useful follow-up to the more basic material they already teach. 


\section{- Teacher confidence and necessary preparation in specific engineering content}

All participating teachers reported enjoying their experiences in the initial two-day teachers workshops. Many teachers (especially in the elementary and middle school levels) offered comments during the focus groups that the exposure to the curriculum materials during the workshop and staff support during the implementation period are what helped make experience a positive one. Some teachers anecdotally admitted initial reluctance, however felt well-supported to attempt implementation.

Phase 2 (Statewide Scale Up) is currently underway and includes: 1) continued dissemination of the Engineering is Elementary, A World in Motion, and Engineering The Future curricula; 2) statewide outreach and professional development for 2,000 K-12 New Jersey classroom teachers in the next three years, 3) expansion of the portfolio of engineering curricula supported and disseminated; 4) development of modular engineering curricula for specific secondary topics; and 5) involvement of administrators, teachers, policymakers, educational organizations, the corporate community, parents, the media, as well as alumni and other friends in the effort to ensure that new educational standards include engineering as a required element of all students' elementary through secondary-level curriculum in New Jersey within five years.

\section{Acknowledgements}

The authors of this paper would like to acknowledge the Society of Automotive Engineers Foundation's continuing support of the EOFNJ project, and all of the New Jersey classroom teachers who participated in the pilot studies.

\section{Bibliographic Information}

[1] Schwartz. D.L. and Black, J.B., "Shuttling between Depictive Models and Abstract Rules," Cognitive Science 20, no. 4 (October-December 1996): 457-497.

[2] Shipstone, D. (1985). Electricity in Simple Circuits (pp. 33-51). In R. Driver, E. Guesne, \& A. Tiberghien (Eds.), Children's Ideas in Science. Philadelphia: Open University Press.

[3] Koumaras, P., Kariotoglou, P., Psillos, D. (1997). Causal structures and counter-intuitive experiments in electricity. International Journal of Science Education, 19 (6), pp. 617-630.

[4] Asami, N., King J., Monk, M. (2000). Tuition and Memory: mental models and cognitive processing in Japanese children's work on d.c. electrical circuits. Research in Science \& Technological Education, 18 (2), pp. 142-152.

[5] Trumper, R. (1997). Applying conceptual conflict strategies in the learning of the energy concept. Research in Science \& Technological Education, 15 (1), On-line document. 